Research Article

\title{
Improvement in Neuropathy Specific Quality of Life in Patients with Diabetes after Vitamin D Supplementation
}

\author{
Uazman Alam, ${ }^{1,2}$ Asher Fawwad, ${ }^{3,4}$ Fariha Shaheen, ${ }^{3}$ Bilal Tahir, ${ }^{3}$ Abdul Basit, ${ }^{3}$ \\ and Rayaz A. Malik ${ }^{5,6,7}$ \\ ${ }^{1}$ Department of Eye and Vision Sciences, Institute of Ageing and Chronic Disease, \\ University of Liverpool and Aintree University Hospital NHS Foundation Trust, Liverpool, UK \\ ${ }^{2}$ Division of Diabetes, Endocrinology and Gastroenterology, School of Medical Sciences, University of Manchester, Manchester, UK \\ ${ }^{3}$ Baqai Institute of Diabetology and Endocrinology, Karachi, Pakistan \\ ${ }^{4}$ Baqai Medical University, Karachi, Pakistan \\ ${ }^{5}$ Weill Cornell Medicine-Qatar, Doha, Qatar \\ ${ }^{6}$ Institute of Cardiovascular Sciences, University of Manchester and Central Manchester Hospital Foundation Trust, Manchester, UK \\ ${ }^{7}$ Manchester Metropolitan University, Manchester, UK
}

Correspondence should be addressed to Rayaz A. Malik; ram2045@qatar-med.cornell.edu

Received 11 August 2017; Revised 23 October 2017; Accepted 2 November 2017; Published 28 December 2017

Academic Editor: Munmun Chattopadhyay

Copyright (C) 2017 Uazman Alam et al. This is an open access article distributed under the Creative Commons Attribution License, which permits unrestricted use, distribution, and reproduction in any medium, provided the original work is properly cited.

\begin{abstract}
Objective. To assess the effect of vitamin D supplementation on neuropathy specific quality of life (NeuroQoL) in patients with painful diabetic neuropathy. Methods. This prospective, open label study was conducted between June 2012 and April 2013. Patients with symptomatic diabetic neuropathy were given a single dose of 600,000 IU intramuscular vitamin D, and NeuroQol was assessed at baseline and at five follow-up visits every 4 weeks. Results. Of 143 participants, $41.3 \%$ were vitamin D deficient (vitamin $\mathrm{D}<20 \mathrm{ng} / \mathrm{ml})$. Treatment with vitamin $\mathrm{D}$ resulted in a significant increase in $25(\mathrm{OH}) \mathrm{D}(P<0.0001)$ and a significant improvement in the NeuroQoL subscale score for emotional distress $(P=0.04)$, with no significant change in the other NeuroQoL domains of painful symptoms and paresthesia, loss of temperature and touch sensation, unsteadiness, limitation in daily activities, and interpersonal problems. There was a significant reduction in patient perception about foot problems on QoL of "quite a lot" $(P<0.05)$ and "very much" $(P<0.0001)$ with a significant reduction in the baseline response of having a "poor" QoL from 5.2\% to $0.7 \%(P<0.0001)$ and an increase in the response of an "excellent QoL" from $1.5 \%$ to $7.4 \%(P<0.0001)$. Conclusion. Vitamin D is effective in improving quality of life in patients with painful diabetic neuropathy.
\end{abstract}

\section{Introduction}

Painful diabetic neuropathy is a major complication of diabetes, characterised by pain, tingling, burning, and cramps in the feet and lower legs with a significant reduction in quality of life [1]. In our previous large population-based study in the UK, the prevalence of painful diabetic neuropathy was $21 \%$ in Europeans but $34 \%$ in South Asians [2]. The prevalence of painful diabetic neuropathy ranges from $50 \%$ in Turkey [3], 22-60\% in the Middle East [4], and 69\% in Pakistan [5]. These differences have been attributed to different populations from primary and secondary care, criteria for diagnosing painful neuropathy, and different patient demographics.

Vitamin D deficiency is more prevalent in South Asians [6], even in people living in South Asia including Pakistan [7], and in Pakistan, the prevalence of vitamin D deficiency ranges from $40 \%$ [8] to $83 \%$ [9]. Vitamin D deficiency itself has been associated particularly with diabetic peripheral neuropathy [10-12] rather than retinopathy or maculopathy $[13,14]$. In a study conducted in Kuwait, vitamin $\mathrm{D}$ deficiency occurred in $\sim 82 \%$ of patients with diabetic neuropathy compared to $\sim 61 \%$ of patients without neuropathy $(P<0.05)[15]$. A meta-analysis has confirmed 
this association and showed an odds ratio of $\sim 2.9$ (95\% CI 1.84-4.50) in favour of diabetic neuropathy in patients with vitamin D deficiency [16]. Recently in China, vitamin D deficiency has also been shown to be an independent risk factor for diabetic peripheral neuropathy [17]. We have recently shown a significant reduction in the severity of painful diabetic neuropathy after treatment with vitamin $\mathrm{D}$ [18].

Patients with diabetes have a worse quality of life (QoL) compared to persons without diabetes [19], especially those with diabetic neuropathy [20]. Painful neuropathy reduces quality of life (QoL) which appears to be mediated through increased anxiety, depression, physical burden, emotional disorders, and limitation of mobility. Relief of neuropathic pain with pharmacological agents has been shown to improve QoL [21-23].

The current study assessed the effect of treatment with a single intramuscular injection of high dose vitamin $\mathrm{D}$ on quality of life in patients with painful diabetic neuropathy using the NeuroQoL questionnaire (a specific validated neuropathy QoL instrument).

\section{Methods}

This was a prospective, open label clinical trial in patients with painful diabetic neuropathy between June 2012 and April 2013 undertaken in the Baqai Institute of Diabetology and Endocrinology (BIDE), a tertiary care diabetes unit in Karachi, Pakistan. The study received ethics approval from the institutional review board (IRB) of BIDE. Study participants gave signed informed consent in keeping with the Declaration of Helsinki.

Patients with symptomatic diabetic neuropathy aged above 18 years and $\mathrm{HbA} 1 \mathrm{c} \leq 11 \%$ with no comorbidities were included in the study after obtaining informed consent. None of the patients were actively receiving vitamin $\mathrm{D}$ supplementation during recruitment. Participants received a single dose of intramuscular vitamin $\mathrm{D}_{3}$ of $600,000 \mathrm{IU}$ and were assessed at five follow-up visits every 4 weeks.

Height, weight (ZT-160 scales, WINCOM, Jiangsu, China), and blood pressure was assessed, and body mass index was calculated using the formula (weight in $\mathrm{kg} / \mathrm{height}$ in $\mathrm{m}^{2}$ ).

The laboratory used internal quality controls for the measurement of 25(OH)D. Serum 25(OH)D was measured using the immunoenzymetric assay, based on a solid phase enzyme-linked immunosorbent assay (ELISA) performed on microtiter plates and was performed exactly as per the manufacturer's instructions. The cross reactivity for vitamin D2 (of the assay) as per manufacturer's assertion was $100 \%$ (relative to vitamin D3), and the assay has excellent correlation to existing globally recognized assays, in combination with good sensitivity and precision (EP17-A Protocols for Determination of Limits of Detection and Limits of Quantitation; approved guideline, standard published by Clinical and Laboratory Standards Institute). The linear range of the assay is $7.7 \mathrm{ng} / \mathrm{ml}$ to $122.9 \mathrm{ng} / \mathrm{ml}$. Inter- and intra-assay variation of the in-house control was $2.5 \%$ and $9.2 \%$, respectively.

Deficiency was defined as a $25(\mathrm{OH}) \mathrm{D}<20 \mathrm{ng} / \mathrm{ml}$, insufficiency as $25(\mathrm{OH}) \mathrm{D}$ values $20-30 \mathrm{ng} / \mathrm{ml}$, and adequacy as a
TABLE 1: Baseline characteristics of patients.

\begin{tabular}{lc}
\hline Baseline characteristics & Total \\
\hline$n$ & 143 \\
Age (years) & $52.3 \pm 11.50$ \\
Male gender, $n$ (\%) & $59(41 \%)$ \\
Type 1 & $7(4.9 \%)$ \\
Type 2 & $136(95.1 \%)$ \\
Duration of diabetes (years) & $12.1 \pm 7.60$ \\
Body mass index (kg/m $\left.{ }^{2}\right)$ & $29.7 \pm 5.8$ \\
Systolic BP (mm/Hg) & $126 \pm 16$ \\
Diastolic BP (mm/Hg) & $80 \pm 9$ \\
Serum creatinine (mg/dl) & $0.98 \pm 0.30$ \\
Calcium (mg/dl) & $8.7 \pm 0.6$ \\
Serum cholesterol (mg/dl) & $169 \pm 41$ \\
Triglyceride (mg/dl) & $134 \pm 80$ \\
High-density lipoprotein (mg/dl) & $39 \pm 10$ \\
Low-density lipoprotein (mg/dl) & $106 \pm 34$ \\
HbAlc (\%) & $8.6 \pm 1.5$ \\
HbAlc (mmol/mol) & $70.2 \pm 16.4$ \\
25(OH)D (ng/ml) & $31.7 \pm 23.2$ \\
Deficient $(<20 \mathrm{ng} / \mathrm{ml})$ & $58(40.6 \%)$ \\
Insufficient $(20-30 \mathrm{ng} / \mathrm{ml})$ & $24(16.8 \%)$ \\
Sufficient $(>30 \mathrm{ng} / \mathrm{ml})$ & $61(42.7 \%)$ \\
\hline
\end{tabular}

Data are presented as $n(\%)$ or mean \pm SD.

$25(\mathrm{OH}) \mathrm{D} \geq 30 \mathrm{ng} / \mathrm{ml}$. These cutoffs are based on the Endocrine Society Clinical Practice Guideline, 2011.

\section{Neuropathy Specific Quality of Life Questionnaire (NeuroQol)}

The NeuroQoL is a specific validated neuropathy and foot ulcer QoL instrument [24, 25] which assesses diabetic neuropathy-related physical and emotional problems affecting daily life and well-being. Each question has a Likert scale of 1 to 5 for frequency of symptoms where 1 represents "never" and 5 represents "all the time." 27 questions were divided into six subscales, that is, painful symptoms and paresthesia; reduction or loss of ability to feel temperature and/or objects with the feet; unsteadiness while standing/ walking; limitation in daily activities; interpersonal problems, for example, physical/emotional dependence on others; and emotional distress. Six questions are related to the patient's perception of symptoms affecting QoL, and two separate questions assess the overall impact of neuropathy on QoL [24].

\section{Statistical Analysis}

All demographic, biochemical, and NeuroQol data were analysed using StatsDirect, Cheshire, UK. The data are presented as mean \pm standard deviation (SD) and median with interquartile range where appropriate. All participants enrolled into the study were included in the analyses with missing data handled by using the Last Observation Carried 


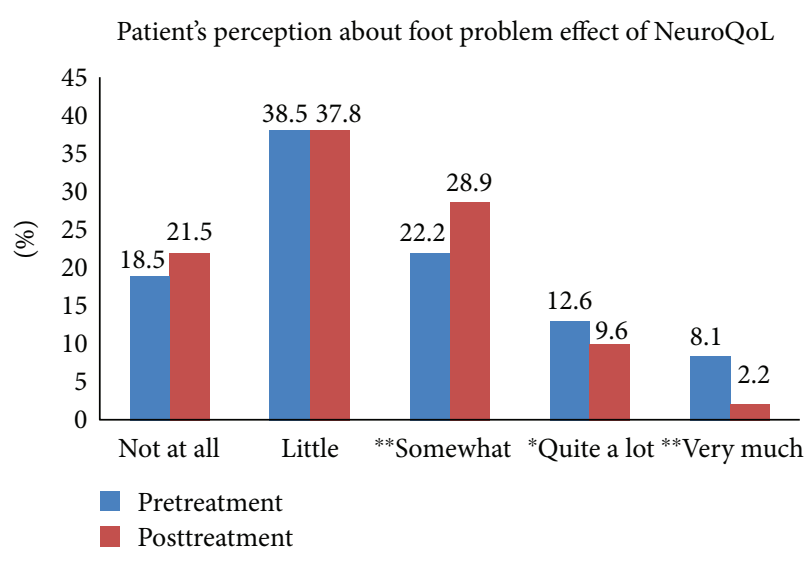

(a)

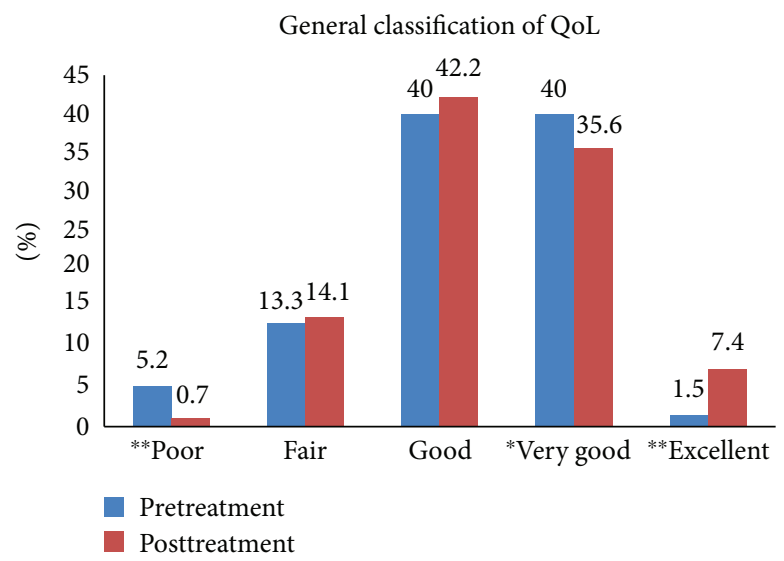

(b)

Figure 1: (a) Comparison of baseline and posttreatment patient's perception on QoL. (b) Comparison of baseline and post treatment general classification on QoL. ${ }^{*} P<0.05,{ }^{* *} P<0.0001$.

TABLE 2: Baseline and end of trial anthropometric and metabolic parameters after administration of vitamin D.

\begin{tabular}{lccc}
\hline Parameters $(n=143)$ & Baseline & Week 20 & $P$ value \\
\hline Body mass index $\left(\mathrm{kg} / \mathrm{m}^{2}\right)$ & $29.7 \pm 5.8$ & $30.2 \pm 7.1$ & NS \\
Systolic BP $(\mathrm{mmHg})$ & $126 \pm 16$ & $123 \pm 15$ & $\mathrm{NS}$ \\
Diastolic BP $(\mathrm{mmHg})$ & $80 \pm 9$ & $78 \pm 7$ & NS \\
HbAlc $(\%)$ & $8.6 \pm 1.5$ & $8.2 \pm 1.5$ & 0.02 \\
HbAlc (mmol/mol) & $70.2 \pm 16.4$ & $66.1 \pm 16.6$ & \\
Creatinine (mg/dl) & $0.98 \pm 0.3$ & $1.01 \pm 0.4$ & NS \\
Calcium (mg/dl) & $8.7 \pm 0.6$ & $8.9 \pm 1.0$ & 0.009 \\
Serum cholesterol (mg/dl) & $169 \pm 41$ & $162 \pm 43$ & NS \\
Triglycerides (mg/dl) & $134 \pm 80$ & $136 \pm 78$ & NS \\
$\begin{array}{l}\text { High-density lipoprotein } \\
\text { (mg/dl) }\end{array}$ & $39 \pm 10$ & $43 \pm 11$ & 0.03 \\
$\begin{array}{l}\text { Low-density lipoprotein } \\
\text { (mg/dl) }\end{array}$ & $106 \pm 34$ & $100 \pm 34$ & NS \\
25(OH)D (ng/ml) & $31.7 \pm 23.2$ & $46.2 \pm 10.2$ & $<0.0001$ \\
\hline
\end{tabular}

Data are presented as mean \pm SD.

Forward (LOCF). Student's $t$-test or nonparametric counterpart and chi-square test were used for analysis of anthropometric, metabolic parameters and patient's perception and general classification of QoL (Table 1, Figures 1(a) and 1(b)). The nonparametric Kruskall-Walis test was utilized with post hoc analyses (Conover-Iman) to test differences in NeuroQoL subscale scores from visit 1 to visit 5. Appropriate statistical tests were employed for both parametric and nonparametric data. Overall $P$ value for multiple comparison tests were kept at 0.05 . A $P$ value of $\leq 0.05$ was considered statistically significant.

\section{Results}

Table 2 summarises the anthropometric and demographic characteristics of the participants. $41 \%$ were males, $4.9 \%$ had type 1 diabetes, and $95.1 \%$ had type 2 diabetes.
The age of participants was $52.3 \pm 11.5$ years, duration of diabetes was $12.1 \pm 7.6$ years, body mass index (BMI) was $29.7 \pm 5.8 \mathrm{~kg} / \mathrm{m}^{2}$, and $\mathrm{HbAlc}$ was $70.2 \pm 16.4 \mathrm{mmol} / \mathrm{mol}$. $40 \%$ had vitamin D deficiency (vitamin $\mathrm{D}<20 \mathrm{ng} / \mathrm{ml}$ ), $17 \%$ had insufficiency (vitamin D 20-30 ng/ml), and $43 \% \mathrm{had}$ sufficient (vitamin $\mathrm{D}>30 \mathrm{ng} / \mathrm{ml}$ ) levels. There were no differences in anthropometric, clinical, and biochemical variables between patients with deficient, insufficient, and sufficient levels of vitamin D.

\section{Effect of Treatment with Vitamin D (Table 1)}

Treatment with vitamin $\mathrm{D}$ resulted in a significant increase in $25(\mathrm{OH}) \mathrm{D}(P<0.0001)$, calcium $(P=0.009)$, and HDL $(P=0.03)$ and a reduction in $\operatorname{HbAlc}(P=0.02)$ (Table 1$)$. There was a significant improvement in the NeuroQoL subscale score for emotional distress by visit $3(P=0.04)$ which was maintained to the end of the study (Table 3 ). There were no significant changes in the other NeuroQoL domains of painful symptoms and paresthesia, loss of temperature and touch sensation, unsteadiness, limitation in daily activities, interpersonal problems, reduced QoL, and total QoL (Table 3).

After stratification of participants into those with sufficient ( $\geq 30 \mathrm{ng} / \mathrm{ml}, n=80)$ and deficient ( $<30 \mathrm{ng} / \mathrm{ml}, n=63$ ) levels of vitamin $\mathrm{D}$ at baseline, we assessed the response to vitamin $\mathrm{D}$ in the NeuroQoL subscale for emotional distress (Table 4). Emotional distress improved significantly only in subjects with a vitamin $\mathrm{D}<30 \mathrm{ng} / \mathrm{ml}(P=0.04)$, whilst those with a baseline vitamin $D$ status $\geq 30 \mathrm{ng} / \mathrm{ml}$ showed no significant change (Table 4). There was no change in any other domain from visit 1 to visit 5 when stratifying subjects based on sufficient $(\geq 30 \mathrm{ng} / \mathrm{ml})$ and deficient $(<30 \mathrm{ng} / \mathrm{ml})$ levels of vitamin $\mathrm{D}$ at baseline. There was also no correlation of baseline vitamin D with individual domains of the NeuroQoL using Kendall's rank correlation.

There was a significant reduction in the patient responses of "quite a lot" $(P<0.05)$ and "very much" $(P<0.0001)$ on patient perception about foot problem effect on QoL 
TABle 3: NeuroQoL measures from baseline to final visit.

\begin{tabular}{|c|c|c|c|c|c|}
\hline NeuroQoL measures & Baseline & $\mathrm{V} 2$ & V3 & V4 & V5 \\
\hline Pain & $11.7 \pm 4.1$ & $11.3 \pm 4.7$ & $11.5 \pm 4.4$ & $11.3 \pm 4.3$ & $11.4 \pm 3.9$ \\
\hline$(-/ 35)$ & $11(9-14)$ & $10(8-13)$ & $10(8-14)$ & $10(8-14)$ & $11(9-13)$ \\
\hline Loss reduction & $4.9 \pm 2.4$ & $4.8 \pm 2.4$ & $4.8 \pm 2.6$ & $4.7 \pm 2.6$ & $4.6 \pm 2.2$ \\
\hline$(-/ 15)$ & $4(3-6)$ & $4(3-6)$ & $4(3-6)$ & $4(3-6)$ & $4(3-5)$ \\
\hline Diffuse sensory-motor symptoms & $6.1 \pm 3.6$ & $6.1 \pm 3.6$ & $6.1 \pm 3.5$ & $6.1 \pm 3.4$ & $6.5 \pm 3.0$ \\
\hline$(-/ 15)$ & $5(3-7)$ & $5(3-8)$ & $5(3-7)$ & $5(3-7)$ & $6(4-8)$ \\
\hline Limitations & $4.5 \pm 2.5$ & $4.6 \pm 2.5$ & $4.2 \pm 1.9$ & $4.2 \pm 2.0$ & $4.1 \pm 2.0$ \\
\hline$(-/ 15)$ & $3(3-5)$ & $3(3-6)$ & $3(3-5)$ & $3(3-5)$ & $3(3-5)$ \\
\hline Interpersonal & $6.3 \pm 3.9$ & $6.3 \pm 4.1$ & $5.6 \pm 3.1$ & $5.9 \pm 3.5$ & $5.6 \pm 3.1$ \\
\hline$(-/ 20)$ & $4(4-7)$ & $4(4-7)$ & $4(4-7)$ & $4(4-7)$ & $4(4-7)$ \\
\hline Emotional distress & $13.4 \pm 8.1$ & $12.1 \pm 7.5$ & $11.0 \pm 6.4$ & $11.0 \pm 6.0$ & $10.8 \pm 5.4$ \\
\hline$(-/ 35)$ & $9(7-20)$ & $7(7-17)$ & $7(7-13)^{*}$ & $7(7-14)^{*}$ & $7(7-15)^{* *}$ \\
\hline R QoL & $12.0 \pm 6.3$ & $11.4 \pm 6.2$ & $11.2 \pm 5.4$ & $11.5 \pm 5.2$ & $11.2 \pm 4.7$ \\
\hline$(-/ 30)$ & $10(7-16)$ & $9(7-15)$ & $9(7-14)$ & $10(7-14)$ & $10(8-13)$ \\
\hline Total QoL & $64.7 \pm 24.3$ & $62.3 \pm 24.9$ & $60.1 \pm 21.8$ & $60.2 \pm 21.7$ & $59.8 \pm 18.2$ \\
\hline$(-/ 135)$ & $57(45-78)$ & $54(44-71)$ & $53(44-70)$ & $54(43-71)$ & $55(45-70)$ \\
\hline
\end{tabular}

Data are presented as mean \pm SD and median (IQR). ${ }^{*} P=0.02$ and ${ }^{* *} P=0.03$.

TABLE 4: Response in emotional distress stratified according to baseline vitamin D status $(<30 \mathrm{ng} / \mathrm{ml}$ and $\geq 30 \mathrm{ng} / \mathrm{ml})$.

\begin{tabular}{|c|c|c|c|c|c|}
\hline NeuroQoL measures & Baseline & $\mathrm{V} 2$ & V3 & $\mathrm{V} 4$ & V5 \\
\hline \multicolumn{6}{|l|}{ Emotional distress } \\
\hline $25(\mathrm{OH}) \mathrm{D}<30 \mathrm{ng} / \mathrm{ml}$ & $13.5 \pm 8.2$ & $11.9 \pm 7.7$ & $10.7 \pm 6.4$ & $10.3 \pm 5.3$ & $10.4 \pm 5.4$ \\
\hline$n=80(-/ 35)$ & $8.5(7-21)$ & $7(7-16)$ & $7(7-11)$ & $7(7-11.5)^{*}$ & $7(7-14)^{*}$ \\
\hline \multicolumn{6}{|l|}{ Emotional distress } \\
\hline $25(\mathrm{OH}) \mathrm{D} \geq 30 \mathrm{ng} / \mathrm{ml}$ & $13.4 \pm 8.1$ & $12.3 \pm 7.2$ & $11.4 \pm 6.5$ & $11.8 \pm 6.8$ & $11.3 \pm 5.4$ \\
\hline$n=63(-/ 35)$ & $10(7-20)$ & $7(7-18)$ & $7(7-15)$ & $7(7-16)$ & $7(7-15)$ \\
\hline
\end{tabular}

Data are presented as mean $\pm \mathrm{SD}$ and median (IQR), ${ }^{*} P=0.04$.

(Figure 1(a)). There was a significant reduction in the baseline response of having a "poor" QoL from 5.2\% to $0.7 \%$ $(P<0.0001)$ and an increase in the response of an "excellent QoL” from $1.5 \%$ to $7.4 \%(P<0.0001)$ (Figure $1(\mathrm{~b})$ ).

\section{Loss to Follow-Up}

Seven participants did not complete at visit 5, two participants at visit 4, one participant at visit 3, and one participant at visit 2 . All participants enrolled into the study were included in subsequent analyses with LOCF for NeuroQol analyses.

\section{Discussion}

Diabetes and painful diabetic neuropathy are associated with reduced quality of life [20, 26-28]. Indeed, in a recent study the Norfolk, Qol-DN score was administered to 21,261 patients and demonstrated a 3-fold reduction in QoL in those with diabetic neuropathy [29]. Neuro-QoL is a validated tool for assessing neuropathy specific quality of life (QoL) in patients with diabetes [24] and has been employed to show an association between diabetic neuropathy and depressive symptoms [30]. The main findings of this study are that administration of a single high-dose treatment with vitamin $\mathrm{D}$ showed a significant improvement in specific NeuroQol subscale of emotional distress, improvements in the self-classification of QoL with fewer subjects classifying their QoL as poor, and "foot problems" causing less perceived reduced QoL. Pharmacological interventions for painful diabetic neuropathy may [28, 31] or may not [32] show an improvement in QoL due to significant side effects. Interestingly, a recent analysis of the COMBO-DN study has shown that treatment with duloxetine was of most benefit in patients without low mood [33].

A previous study has shown an improvement in pain, sleep, and quality of life after treatment with vitamin $D$ in subjects with chronic pain [34]. We and others have demonstrated an improvement in pain-related symptom scores in diabetic patients with painful neuropathy after treatment with vitamin D $[18,35]$. NeuroQoL is a neuropathy-specific QoL tool for the assessment and follow-up of therapeutic interventions in clinical trials of painful diabetic neuropathy. The SF-12 questionnaire has shown a profound effect on the physical and mental components of QoL in diabetic 
neuropathy [36]. However, the NeuroQoL physical symptom and psychosocial functioning scales shows stronger associations than the SF-12 with the clinical indicators of neuropathic severity, by mediating more fully the relationship of neuropathy to overall quality of life and explaining additional variance beyond that accounted for by the SF-12 measures [24].

In the present study, treatment with vitamin $\mathrm{D}$ resulted in an improvement in emotional distress after $\sim 12$ weeks, especially in those with low levels of vitamin D, suggesting a biological basis for this response [37]. Furthermore, patient perception of the general and more specific effect of foot problems on QoL was improved, suggesting that even small improvements in objective measures of neuropathic pain may improve QoL. Of course, even modest improvements in pain can produce clinically meaningful changes in function and status [38]. Whilst we [16] and others [26] have previously shown an improvement in the severity of painful neuropathic symptoms, in the present study, the subscale for positive and negative symptoms did not change, possibly because they evaluated the frequency rather than severity of these symptoms. Indeed, in a recent placebo-controlled study, treatment with vitamin $\mathrm{D}$ was associated with an improvement in positive neuropathic symptoms with no effect on neuropathic deficits or nerve conduction [10]. In relation to a lack of benefit on unsteadiness, we have recently shown no association between vitamin $\mathrm{D}$ deficiency and lower limb muscle strength or volume [39].

Increasing evidence suggests that an adequate intake of vitamin $\mathrm{D}$ should be encouraged particularly in populations at risk of vitamin D deficiency [10-12]. In the present study, we have shown an improvement in vitamin D levels as well as HbA1c and HDL [40], with an impact on neuropathy specific QoL.

This is an open label intervention study in a population attending a secondary care setting and therefore cannot be generalised to the whole diabetic population. We also cannot exclude a placebo response particularly as subjects received regular follow-up after a known active intervention, although the improvement was observed several weeks after treatment had commenced. We believe that the data warrant a larger double-blind placebo-controlled clinical trial with vitamin $\mathrm{D}$ to assess the benefits on painful neuropathic symptoms and QoL.

\section{Conclusion}

A significantly improved neuropathy-specific quality of life is observed following a single high-dose intramuscular treatment with vitamin D3 in patients with painful diabetic neuropathy, particularly those with vitamin D deficiency.

\section{Additional Points}

Key Message. Vitamin D may play an important role in the treatment of painful diabetic neuropathy in relation to quality of life. A single high-dose intramuscular injection of vitamin D3 provides significant improvements in neuropathy-specific aspects of the quality of life in patients with diabetic neuropathy. Research Questions. Are the quality of life improvements maintained over a longer period time? Through which central mechanism(s) does vitamin D cause improvement in quality of life? Are the same findings replicated in a randomised placebo controlled trial? Guarantor of Data and Manuscript. Asher Fawwad is the guarantor of this work and, as such, had full access to all the data in the study and takes responsibility for the integrity of the data and the accuracy of the data analysis.

\section{Disclosure}

Uazman Alam and Asher Fawwad are co-first authors.

\section{Conflicts of Interest}

The authors declare that they have no conflicts of interest.

\section{Authors' Contributions}

Asher Fawwad contributed to the concept and design of the manuscript, supervised the project, and wrote and reviewed the manuscript. Uazman Alam conceived the study, undertook the data analyses, and reviewed and revised the manuscript. Fariha Shaheen analyzed the data and wrote and reviewed the manuscript. Bilal Tahir was the study coordinator, researched the data, and wrote the manuscript. Abdul Basit contributed to the concept and design of the manuscript, helped in the clinical and neurological assessment, and reviewed and revised the manuscript. Rayaz A. Malik conceived the study, supervised the project, undertook the data analyses, and reviewed and revised the manuscript.

\section{References}

[1] A. Sadosky, C. Schaefer, R. Mann et al., "Burden of illness associated with painful diabetic peripheral neuropathy among adults seeking treatment in the US: results from a retrospective chart review and cross-sectional survey," Diabetes, Metabolic Syndrome and Obesity: Targets and Therapy, vol. 6, pp. 79-92, 2013.

[2] C. A. Abbott, R. A. Malik, E. R. E. van Ross, J. Kulkarni, and A. J. M. Boulton, "Prevalence and characteristics of painful diabetic neuropathy in a large community-based diabetic population in the U.K," Diabetes Care, vol. 34, no. 10, pp. 2220-2224, 2011.

[3] A. Celikbilek, A. Y. Gocmen, N. Tanik et al., "Decreased serum vitamin $\mathrm{D}$ levels are associated with diabetic peripheral neuropathy in a rural area of Turkey," Acta Neurologica Belgica, vol. 115, no. 1, pp. 47-52, 2015.

[4] D. D. Wang, B. A. Bakhotmah, H. FB, and H. A. Alzahrani, "Prevalence and correlates of diabetic peripheral neuropathy in a Saudi Arabic population: a cross-sectional study," PLoS One, vol. 9, no. 9, article e106935, 2014.

[5] A. Ali, F. Iqbal, A. Taj, Z. Iqbal, M. J. Amin, and Q. Z. Iqbal, "Prevalence of microvascular complications in newly diagnosed patients with type 2 diabetes," Pakistan Journal of Medical Sciences, vol. 29, no. 4, pp. 899-902, 2013. 
[6] U. Alam, O. Najam, S. Al-Himdani et al., "Marked vitamin D deficiency in patients with diabetes in the UK: ethnic and seasonal differences and an association with dyslipidaemia," Diabetic Medicine, vol. 29, no. 10, pp. 1343-1345, 2012.

[7] A. Arabi, R. El Rassi, and G. El-Hajj Fuleihan, "Hypovitaminosis D in developing countries-prevalence, risk factors and outcomes," Nature Reviews Endocrinology, vol. 6, no. 10, pp. 550-561, 2010.

[8] S. A. Jawaid and M. Jawaid, "Management of diabetic foot ulcers: some bitter facts and harsh realities," Pakistan Journal of Medical Sciences, vol. 22, pp. 97-100, 2006.

[9] A. Sheikh, Z. Saeed, S. A. D. Jafri, I. Yazdani, and S. A. Hussain, "Vitamin D levels in asymptomatic adults-a population survey in Karachi, Pakistan," PLoS One, vol. 7, no. 3, article e33452, 2012.

[10] D. Shehab, K. Al-Jarallah, N. Abdella, O. A. Mojiminiyi, and H. Al Mohamedy, "Prospective evaluation of the effect of short-term oral vitamin D supplementation on peripheral neuropathy in type 2 diabetes mellitus," Medical Principles and Practice, vol. 24, no. 3, pp. 250-256, 2015.

[11] L. H. Soderstrom, S. P. Johnson, V. A. Diaz, and A. G. Mainous 3rd, "Association between vitamin D and diabetic neuropathy in a nationally representative sample: results from 2001-2004 NHANES," Diabetic Medicine, vol. 29, no. 1, pp. 50-55, 2012.

[12] S. Skalli, M. Muller, S. Pradines, S. Halimi, and N. WionBarbot, "Vitamin D deficiency and peripheral diabetic neuropathy," European Journal of Internal Medicine, vol. 23, no. 2, pp. e67-e68, 2012.

[13] U. Alam, V. Arul-Devah, S. Javed, and R. A. Malik, "Vitamin D and diabetic complications: true or false prophet?" Diabetes Therapy, vol. 7, no. 1, pp. 11-26, 2016.

[14] U. Alam, Y. Amjad, A. W. Chan, O. Asghar, I. N. Petropoulos, and R. A. Malik, "Vitamin D deficiency is not associated with diabetic retinopathy or maculopathy," Journal of Diabetes Research, vol. 2016, Article ID 6156217, 7 pages, 2016.

[15] D. Shehab, K. Al-Jarallah, O. A. Mojiminiyi, H. Al Mohamedy, and N. A. Abdella, "Does vitamin D deficiency play a role in peripheral neuropathy in type 2 diabetes?," Diabetic Medicine, vol. 29, no. 1, pp. 43-49, 2012.

[16] W. S. Lv, W. J. Zhao, S. L. Gong et al., "Serum 25hydroxyvitamin D levels and peripheral neuropathy in patients with type 2 diabetes: a systematic review and metaanalysis," Journal of Endocrinological Investigation, vol. 38, no. 5, pp. 513-518, 2015.

[17] R. He, Y. Hu, H. Zeng et al., "Vitamin D deficiency increases the risk of peripheral neuropathy in Chinese patients with type 2 diabetes," Diabetes/Metabolism Research and Reviews, vol. 33, no. 2, article e2820, 2017.

[18] A. Basit, K. A. Basit, A. Fawwad et al., "Vitamin D for the treatment of painful diabetic neuropathy," BMJ Open Diabetes Research \& Care, vol. 4, no. 1, article e000148, 2016.

[19] R. R. Rubin and M. Peyrot, "Quality of life and diabetes," Diabetes/Metabolism Research and Reviews, vol. 15, no. 3, pp. 205-218, 1999.

[20] S. J. Benbow, M. E. Wallymahmed, and I. A. MacFarlane, "Diabetic peripheral neuropathy and quality of life," QJM: An International Journal of Medicine, vol. 91, no. 11, pp. 733-737, 1998.

[21] A. Moore, P. Wiffen, and E. Kalso, "Antiepileptic drugs for neuropathic pain and fibromyalgia," JAMA, vol. 312, no. 2, pp. 182-183, 2014.
[22] M. Backonja, A. Beydoun, K. R. Edwards et al., "Gabapentin for the symptomatic treatment of painful neuropathy in patients with diabetes mellitus: a randomized controlled trial," JAMA, vol. 280, no. 21, pp. 1831-1836, 1998.

[23] J. Boyle, M. E. V. Eriksson, L. Gribble et al., "Randomized, placebo-controlled comparison of amitriptyline, duloxetine, and pregabalin in patients with chronic diabetic peripheral neuropathic pain: impact on pain, polysomnographic sleep, daytime functioning, and quality of life," Diabetes Care, vol. 35, no. 12, pp. 2451-2458, 2012.

[24] L. Vileikyte, M. Peyrot, C. Bundy et al., "The development and validation of a neuropathy- and foot ulcer-specific quality of life instrument," Diabetes Care, vol. 26, no. 9, pp. 2549-2555, 2003.

[25] S. C. Smith, D. L. Lamping, and G. D. H. Maclaine, "Measuring health-related quality of life in diabetic peripheral neuropathy: a systematic review," Diabetes Research and Clinical Practice, vol. 96, no. 3, pp. 261-270, 2012.

[26] C. I. Bondor, I. A. Veresiu, B. Florea, E. J. Vinik, A. I. Vinik, and N. A. Gavan, "Epidemiology of diabetic foot ulcers and amputations in Romania: results of a cross-sectional quality of life questionnaire based survey," Journal of Diabetes Research, vol. 2016, Article ID 5439521, 7 pages, 2016.

[27] B. S. Galer, A. Gianas, and M. P. Jensen, "Painful diabetic polyneuropathy: epidemiology, pain description, and quality of life," Diabetes Research and Clinical Practice, vol. 47, no. 2, pp. 123-128, 2000.

[28] A. Vinik, B. Emir, R. Cheung, and E. Whalen, "Relationship between pain relief and improvements in patient function/ quality of life in patients with painful diabetic peripheral neuropathy or postherpetic neuralgia treated with pregabalin," Clinical Therapeutics, vol. 35, no. 5, pp. 612-623, 2013.

[29] A. I. Veresiu, C. I. Bondor, B. Florea, E. J. Vinik, A. I. Vinik, and N. A. Gavan, "Detection of undisclosed neuropathy and assessment of its impact on quality of life: a survey in 25,000 Romanian patients with diabetes," Journal of Diabetes and its Complications, vol. 29, no. 5, pp. 644-649, 2015.

[30] L. Vileikyte, H. Leventhal, J. S. Gonzalez et al., "Diabetic peripheral neuropathy and depressive symptoms: the association revisited," Diabetes Care, vol. 28, no. 10, pp. 2378-2383, 2005.

[31] A. Boyd, C. Casselini, E. Vinik, and A. Vinik, "Quality of life and objective measures of diabetic neuropathy in a prospective placebo-controlled trial of ruboxistaurin and topiramate," Journal of Diabetes Science and Technology, vol. 5, no. 3, pp. 714-722, 2011.

[32] J. Boyle, M. E. V. Eriksson, L. Gribble et al., "Randomized, placebo-controlled comparison of amitriptyline, duloxetine, and pregabalin in patients with chronic diabetic peripheral neuropathic pain: impact on pain, polysomnographic sleep, daytime functioning, and quality of life," Diabetes Care, vol. 35, no. 12, pp. 2451-2458, 2012.

[33] P. Marchettini, S. Wilhelm, H. Petto et al., "Are there different predictors of analgesic response between antidepressants and anticonvulsants in painful diabetic neuropathy?," European Journal of Pain, vol. 20, no. 3, pp. 472-482, 2016.

[34] W. Huang, S. Shah, Q. Long, A. K. Crankshaw, and V. Tangpricha, "Improvement of pain, sleep, and quality of life in chronic pain patients with vitamin D supplementation," The Clinical Journal of Pain, vol. 29, no. 4, pp. 341347, 2013. 
[35] P. Lee and R. Chen, "Vitamin D as an analgesic for patients with type 2 diabetes and neuropathic pain," Archives of Internal Medicine, vol. 168, no. 7, pp. 771-772, 2008.

[36] K. Van Acker, D. Bouhassira, D. De Bacquer et al., "Prevalence and impact on quality of life of peripheral neuropathy with or without neuropathic pain in type 1 and type 2 diabetic patients attending hospital outpatients clinics," Diabetes \& Metabolism, vol. 35, no. 3, pp. 206-213, 2009.

[37] M. B. Humble, "Vitamin D, light and mental health," Journal of Photochemistry and Photobiology B: Biology, vol. 101, no. 2, pp. 142-149, 2010.

[38] M. Gore, N. A. Brandenburg, E. Dukes, D. L. Hoffman, K.-S. Tai, and B. Stacey, "Pain severity in diabetic peripheral neuropathy is associated with patient functioning, symptom levels of anxiety and depression, and sleep," Journal of Pain and Symptom Management, vol. 30, no. 4, pp. 374-385, 2005.

[39] M. M. Almurdhi, N. D. Reeves, F. L. Bowling, A. J. Boulton, M. Jeziorska, and R. A. Malik, "Reduced lower-limb muscle strength and volume in patients with type 2 diabetes in relation to neuropathy, intramuscular fat, and vitamin D levels," Diabetes Care, vol. 39, no. 3, pp. 441-447, 2016.

[40] U. Alam, A. W. Chan, A. Buazon et al., "Differential effects of different vitamin $\mathrm{D}$ replacement strategies in patients with diabetes," Journal of Diabetes and its Complications, vol. 28, no. 1, pp. 66-70, 2014. 


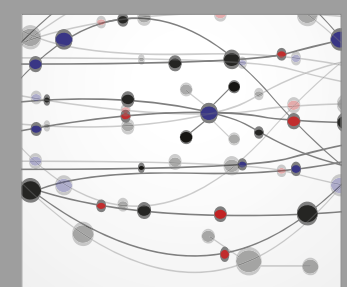

The Scientific World Journal
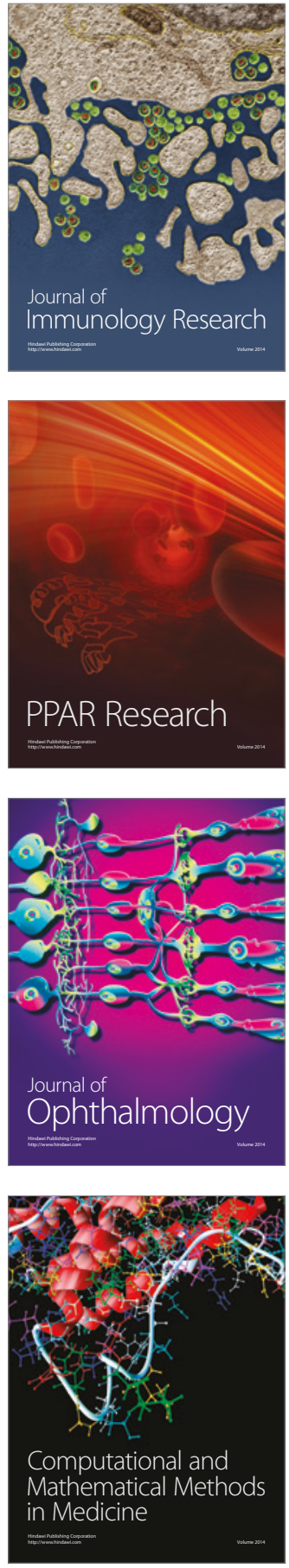

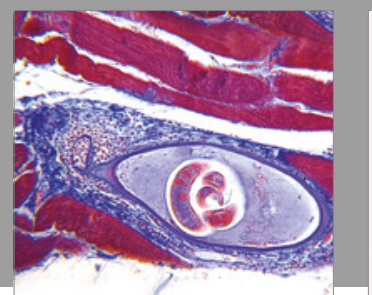

Gastroenterology Research and Practice
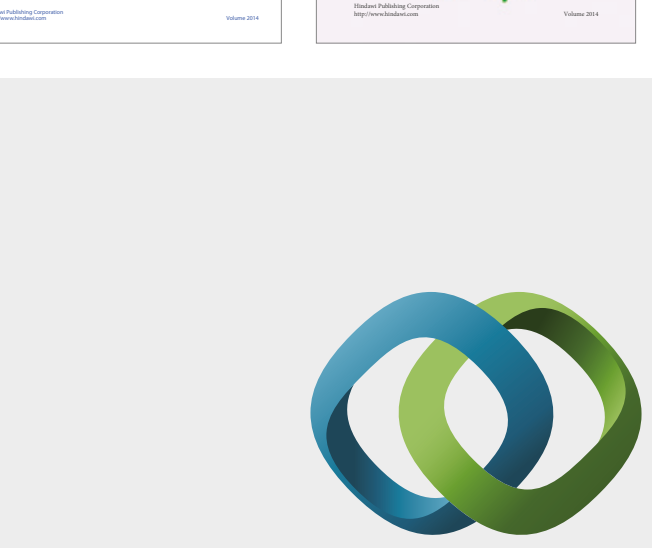

\section{Hindawi}

Submit your manuscripts at

https://www.hindawi.com
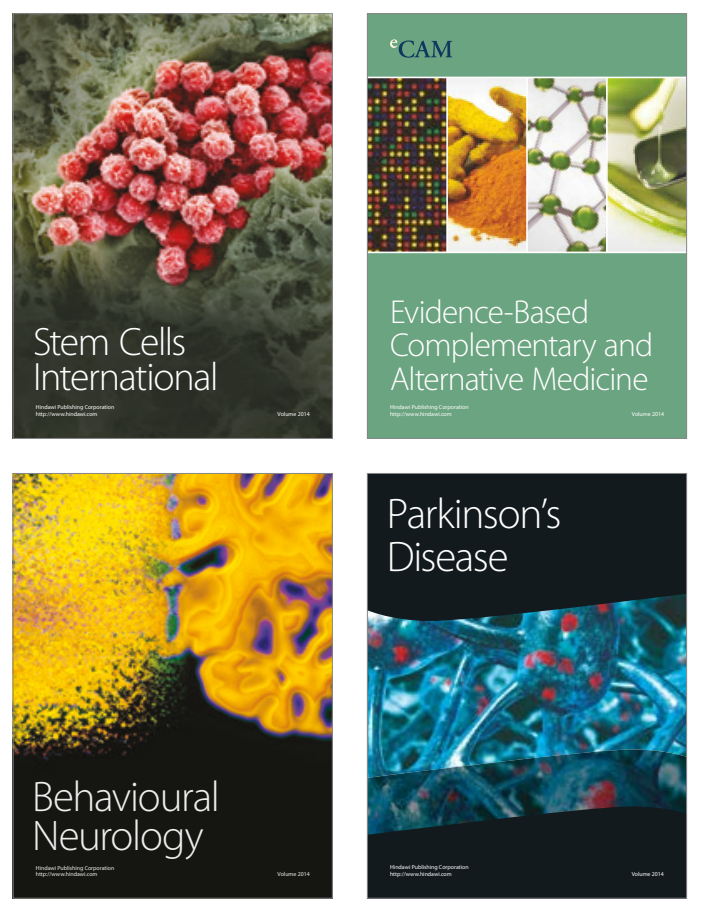
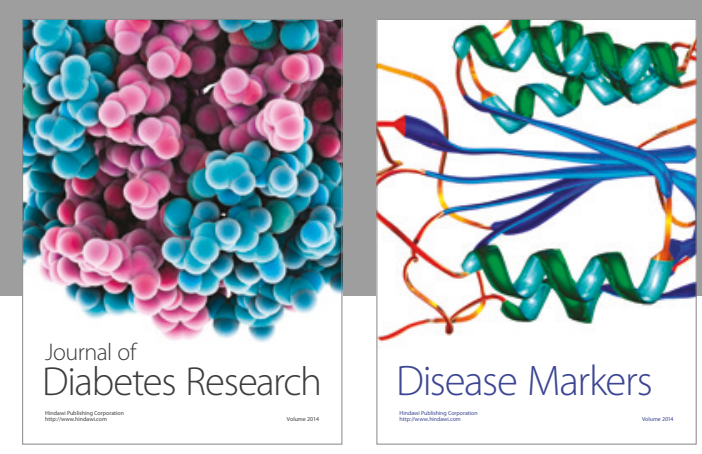

Disease Markers
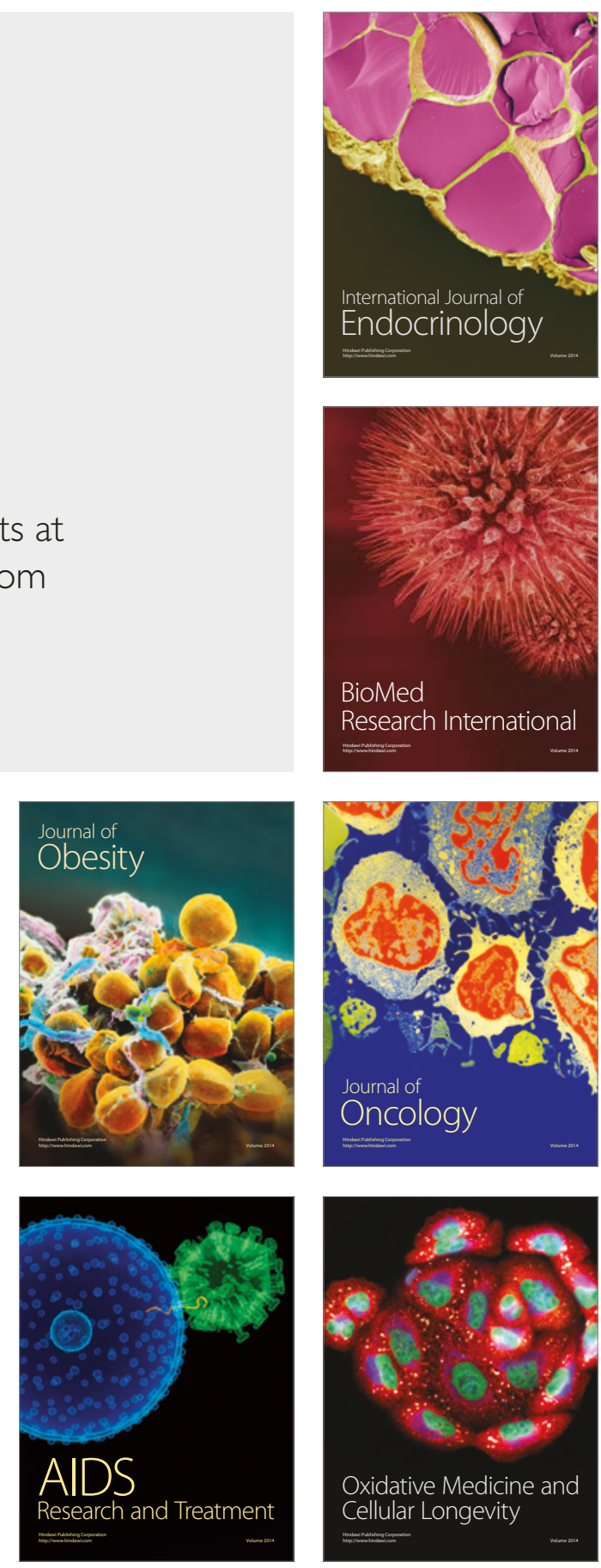